Published in final edited form as:

AIDS Care. 2015 ; 27(10): 1289-1297. doi:10.1080/09540121.2015.1050987.

\title{
Repeat pregnancy in women with HIV infection in Latin America and the Caribbean
}

\section{Regis Kreitchmann, MD, PhD,} Irmandade da Santa Casa de Misericordia de Porto Alegre, Porto Alegre, RS, Brazil, Professor Annes Dias 285, 90020090, Phone/Fax: 555132148008

\section{Karen Megazzini, DrPH, PA,}

Westat, 1600 Research Blvd, Rockville, MD, 20850, USA, Tel: +1 3013666238

\section{Victor Hugo Melo, MD, PhD,}

School of Medicine, Federal University of Minas Gerais, Belo Horizonte, Brazil, Av. Alfredo Balena 190, 2th floor, Tel: +553134099763

\section{Débora Fernandes Coelho, MN, PhD,} Irmandade da Santa Casa de Misericordia de Porto Alegre, Rua Professor Annes Dias, $2954^{\circ}$ floor, Porto Alegre, RS, Brazil 90020-090, Tel/Fax: 55513214.8008

\section{Heather Watts, MD,}

Office of the Global AIDS Coordinator, U.S. Department of State, Washington D.C., Tel: +1202 6632547

\section{Margot Krauss, MD, MPH,}

Westat, 1600 Research Blvd, Rockville, MD, 20850, USA, Tel: +1 3012794513

\section{Maria Isabel Gouvea, MD, MSc,}

Hospital Federal dos Servidores do Estado, Rua Sacadura Cabral, 178, Anexo IV, 4 andar, Rio de Janeiro, RJ - CEP 20221903, Brazil, Tel: 5521 2233-0018 - Fax 5521 2233-1551

\section{Geraldo Duarte, MD, PhD,}

Faculty of Medicine of Ribeirão Preto, University of São Paulo, Ribeirão Preto, Brazil, Avenida Bandeirantes 3900, Ribeirão Preto, São Paulo, Brazil, CEP: 14049-900, Tel: +55 1636022588

Marcelo H. Losso, MD, and HIV Unit, Hospital General de Agudos Jose Maria Ramos Mejia, Buenos Aires, Argentina, Urquiza 609, Pabellon de Clinicas, 2 Piso, C1221ADC Buenos Aires, Argentina, Tel: +5411 4127 0418

\section{George K. Siberry, MD, MPH}

\footnotetext{
Correspondence to: Regis Kreitchmann, regis.kr@terra.com.br.

Disclosure Statement: All authors report that they do not have any financial interest nor will they benefit from the direct application of their research.

The findings and conclusions in this report are those of the authors and do not necessarily represent the views of the National Institutes of Health, the U.S. Department of State, or the Department of Health and Human Services.
} 
Maternal Pediatric Infectious Disease (MPID) Branch, Eunice Kennedy Shriver National Institute of Child Health and Human Development (NICHD), National Institutes of Health, 6100 Executive Blvd., Room 4B11H, Bethesda, MD 20892-7510, Tel: +1 3014967350

Regis Kreitchmann: regis.kr@terra.com.br; Karen Megazzini: karenmegazzini@westat.com; Victor Hugo Melo: victormelo@terra.com.br; Débora Fernandes Coelho: deby.nh@terra.com.br; D. Heather Watts: wattsdh@state.gov; Margot Krauss: margotkrauss@westat.com; Maria Isabel Gouvea: bebelsgouvea@uol.com.br; Geraldo Duarte: gduarte@fmrp.usp.br; Marcelo H. Losso: mlosso@hivramos.org.ar; George K. Siberry: siberryg@mail.nih.gov

\section{Abstract}

Intended and unintended pregnancies occur frequently among HIV-infected women. We evaluated the occurrence of repeat pregnancy and characteristics associated with this outcome among HIVinfected women in Latin America and the Caribbean who were participating in the National Institute of Child Health and Human Development (NICHD) International Site Development Initiative (NISDI). Of the $1342 \mathrm{HIV}$-infected pregnant women enrolled in NISDI, 124 (9.2\%) had one or more repeat pregnancies on study. Median time between the index delivery and date of conception of the subsequent pregnancy was 1.4 years (range 0.1-5.7). Younger age [odds ratio $(\mathrm{OR})=1.07,95 \%$ confidence interval $(\mathrm{CI}): 1.04-1.11$ per one-year decrease in age], hospitalization during the index pregnancy or up to 6 months postpartum [OR=2.0, 95\% CI: 1.2-3.4], and poor index pregnancy outcome (stillbirth or spontaneous/therapeutic abortion) [OR=3.4, 95\% CI: 1.48.4] were associated with increased occurrence of repeat pregnancy in multivariable analysis. Among women with repeat pregnancies, the proportion receiving antiretroviral treatment (versus prophylaxis) increased from $39.4 \%$ at the time of the index pregnancy to $81.8 \%$ at the time of the repeat pregnancy $(\mathrm{p}<0.001)$. These results can help identify women most likely to benefit from reproductive counseling in order to assist with healthy pregnancy planning and prevention of unintended pregnancies.

\section{Keywords}

HIV; predictors of repeat pregnancy; pregnancy; Latin America

\section{Introduction}

An increasing number of women are living with human immunodeficiency virus (HIV) worldwide and in some regions infected women outnumber infected men (WHO, 2012). Since the great majority of these women are of reproductive age, both intended and unintended pregnancies occur frequently in this population and may be increasing in the context of longer survival obtained by the use of highly active antiretroviral therapy (HAART) (Blair, Hanson, Jones, \& Dworkin, 2004; Massad et al., 2004).

Many factors contribute to whether a woman with HIV infection becomes pregnant. Before HAART was available in the United States, Kline et al (1995) documented that significant predictors of a pregnancy subsequent to an HIV-1 diagnosis included younger age, shorter interval since HIV diagnosis, higher number of previous live births, partner's desire for children, and unknown HIV status of the partner (Kline, Strickler, \& Kempf, 1995). These authors predicted that biomedical and non-biomedical factors play a role in becoming pregnant and that the profile of HIV-1-infected women who became pregnant would change 
as the epidemic evolved. Advances in the prevention of mother-to-child transmission and improvements in HIV treatment outcomes are also likely to have an influence on the reproductive choices of women living with HIV, including decisions about number of pregnancies (Gange et al., 2002; Marcellin et al., 2010; Read et al., 2007). For women with HIV infection, the high risk of adverse pregnancy outcomes, including preterm deliveries, low birth weight, small for gestational age, stillbirths and neonatal deaths, may also affect their decisions about subsequent pregnancies (Ekouevi et al., 2008; Kreitchmann et al., 2014; Kupka et al., 2009; Young et al., 2012).

In a recent prospective cohort study in HIV-infected women from Rio de Janeiro, pregnancy was more likely among younger women and those living with a partner, while it was less likely among women with higher education level and those who were receiving antiretroviral therapy (Friedman et al., 2011).

In the Women and Infants Transmission Study (WITS), repeat pregnancy was associated with younger age, lower educational status, higher CD4\%, and lower viral load (Bryant et al., 2007). On the other hand, another US study of HIV-infected women found that the only risk factor for repeat pregnancy was the use of male condoms as the sole contraceptive agent (Watts, Huang, Cohn, Smith, \& Hitti, 2009). Repeat pregnancies in HIV-infected women from Ireland and United Kingdom occurred more frequently in women of younger age, those with higher parity and those who were born in Central or Western Africa (French, Cortina-Borja, Thorne, \& Tookey, 2012).

Few studies have evaluated demographics and health status of HIV-infected women experiencing repeat pregnancies and there is limited information from Latin American in the era of routine use of HAART. The goal of this study was to describe the occurrence of repeat pregnancies in this cohort and to identify characteristics associated with this outcome.

\section{Materials and Methods}

Between 2002 and 2011 the Eunice Kennedy Shriver National Institute of Child Health and Human Development (NICHD) International Site Development Initiative (NISDI) prospectively followed two sequential cohorts of HIV-infected women and their perinatally exposed, but HIV-uninfected infants at 19 clinical sites in Latin America and the Caribbean (Read et al., 2012). The first cohort (the Perinatal Protocol) enrolled HIV-infected pregnant women between 2002 and 2007 and followed the women and their uninfected infants until six months post-partum or study discontinuation. Women could voluntarily re-enroll with subsequent pregnancies into this protocol or a follow-on protocol (NISDI Longitudinal Study in Latin American Countries, LILAC) between 2008 and 2009. Mother-infant pairs enrolled in LILAC were followed until study site discontinuation or study close out in November 2011. During each visit, clinical and laboratory data were collected using standardized case reports forms (CRFs). The NICHD Institutional Review Board (IRB), the data management and statistical center IRB, ethics committees at each clinical site, and national review boards (where required, e.g., Brazil) reviewed and approved the protocols. Informed consent was obtained from all participants. 
Women enrolled into NISDI were eligible for the analysis with the exception of those who underwent sterilization around the time of their index delivery or had less than 12 months of potential follow-up after their index delivery due to death, site closure, or study discontinuation. The first pregnancy on study was considered the index pregnancy. A repeat pregnancy was a pregnancy that occurred after the index pregnancy. If a woman had more than one repeat pregnancy on study, only data from the first repeat pregnancy was used in the analysis.

Simple descriptive statistics were used to describe the characteristics of the women at enrollment, according to whether or not they had a repeat pregnancy. This included the median and interquartile range for continuous measures and the frequency and percent for categorical characteristics. The outcome of interest was the occurrence of repeat pregnancy. The nonparametric Mann-Whitney test was used to assess the significance of associations of continuous-scaled demographic and clinical measures with repeat pregnancy and the Fisher's exact test for categorical measures. Variables associated with repeat pregnancy in the univariate analyses at $p \leq 0.2$ were initially included in the multivariable logistic regression models. We then used stepwise selection and backward elimination methods to determine the most parsimonious model. Only variables with a p-value $<0.05$ remained in the final model.

In subset analyses, we describe differences in the maternal characteristics and infant outcomes at the time of the index versus repeat pregnancy for women who had a subsequent pregnancy on study. Women were excluded from this subset analysis if they were not reenrolled on study at the time of their first repeat pregnancy since enrollment data (such as employment status, marital status, drug and alcohol use, viral load and antiretroviral (ARV) history) would not be available for the time of the repeat pregnancy. This occurred predominantly among women who had subsequent pregnancies while already enrolled in the LILAC cohort (so enrollment data was not recollected) and to a lesser extent among women who had documentation of an unenrolled repeat pregnancy. McNemar's test was used to compare categorical outcomes and the paired t-test was used for the analysis of continuous outcomes. Statistical analyses were performed using SAS version 9.2 software (SAS Institute Inc., Cary, NC, USA).

\section{Results}

Of $1548 \mathrm{HIV}$-infected pregnant women enrolled into the NISDI perinatal protocols, 206 women were excluded from the analysis (Figure 1). Among the final study population of $1342,1218(90.8 \%)$ had one pregnancy on study and $124(9.2 \%)$ had two or more pregnancies on study. The median interval between index delivery and estimated date of conception of the subsequent pregnancy was 1.4 years (range 0.1 to 5.7 years).

The characteristics of the study population and their associations with repeat pregnancy status are shown in Table 1. Overall, the majority of the 1342 women were from Brazil $(n=934)$ and Argentina $(n=309)$. Repeat pregnancy was most common among women from Argentina (16.2\%) who contributed 40\% (50 of 124) of the repeat pregnancies in the analysis. Women who went on to have a second pregnancy on study were younger at 
enrollment (median age 26 vs. 28 years, $\mathrm{p}<0.001$ ) than those not having a repeat pregnancy. Those women who had been on antiretroviral drugs prior to enrollment for their index pregnancy were less likely to have a repeat pregnancy than those not ARV experienced at enrollment ( $8.1 \%$ vs. $12.5 \%$, $\mathrm{p}=0.05$ ). Repeat pregnancies were more likely to occur among women reporting illicit drug use during their index pregnancy (20.8\% vs. $8.8 \%$ for those not reporting such use, $\mathrm{p}=0.007$ ), those having experienced a hospitalization during the index pregnancy or up to 6 months postpartum $(15.6 \%$ vs. $8.6 \%, \mathrm{p}=0.01)$, and those who had their index pregnancy end in stillbirth or spontaneous abortion $(22.6 \%$ vs. $8.9 \%, \mathrm{p}=0.02)$.

Multivariable analyses included all factors associated with repeat pregnancy in the bivariable analyses at the pre-specified level of $p<0.20$; country of origin was not included in the modeling since the small numbers of repeat pregnancies reported in Peru ( $\mathrm{n}=5)$, Mexico $(\mathrm{n}=0)$, and the Bahamas $(\mathrm{n}=0)$ would have led to model failure. For each one-year decrease in age at initial enrollment, women were $7 \%$ more likely to have a repeat pregnancy [odd ratio (OR) 1.07, 95\% confidence interval (CI): 1.04-1.11; $<<0.0001$ ] (Table 2). Having been hospitalized during the index pregnancy or up to 6 months postpartum and having the index pregnancy end in a stillbirth or spontaneous or therapeutic abortion were both associated $(\mathrm{p}<0.01)$ with an increased likelihood of having a repeat pregnancy (OR 2.0, 95\% CI: $1.2-$ 3.4 and OR 3.4, 95\% CI: 1.4-8.4, respectively).

We compared maternal characteristics and infant outcomes at the time of the index and repeat pregnancy for 77 of the 124 women who had a second pregnancy. Forty seven women who experienced a repeat pregnancy were not eligible for this analysis because they did not re-enroll into NISDI with their subsequent pregnancy. Among those included in the analysis, the proportion of women who received antiretroviral treatment (versus prophylaxis) increased from $39.4 \%$ at the time of the index pregnancy to $81.8 \%$ at the time of the repeat pregnancy ( $\mathrm{p}<0.001$ ). Similarly, the proportion of women with a viral load $\geq 400 \mathrm{copies} / \mathrm{mL}$ declined from $68.9 \%$ at enrollment for their index pregnancy to $54.1 \%$ at enrollment for their subsequent pregnancy $(\mathrm{p}=0.04)$. Lastly, the proportion of women who reported drinking alcohol during pregnancy decreased from $13.3 \%$ during the index pregnancy to $4.0 \%$ during the subsequent pregnancy $(\mathrm{p}=0.04)$. There was no significant difference in the proportion of births that ended in stillbirth or abortion (6.5\% of index pregnancies versus $6.5 \%$ of repeat pregnancies, $\mathrm{p}>0.99$ ). We did not find any differences in gestational age at delivery, infant birth weight, or HIV transmission rates, but these comparisons are limited by the relatively small number of patients and consequent limited statistical power to detect differences.

\section{Discussion}

In this study, we evaluated the frequency of repeat pregnancies in women infected with HIV in a multi-country Latin American context where antiretroviral therapy is available. Significant associations with repeat pregnancy included younger age, being hospitalized during the index pregnancy or up to six months postpartum, and having an index pregnancy end in stillbirth or abortion. Women reporting illicit drug use at their index pregnancy were also twice as likely to have a repeat pregnancy, although this association did not remain significant in the multivariable model. 
The association of younger age with repeat pregnancy is consistent with previous studies and with general population patterns (Marcellin et al., 2010; Paiva et al., 2007). Similarly, it was noted that having an index pregnancy that did not result in a live birth was an important predictor of having a repeat pregnancy. This finding was previously described (Suryavanshi et al., 2008) and it is important to note that adverse birth outcomes occur more frequently in HIV-infected women than in those without HIV (Aaron et al., 2012; Ekouevi et al., 2008; Kupka et al., 2009; Paiva et al., 2007; Young et al., 2012).

Hospitalization during the index pregnancy or up to 6 month postpartum was associated with an increased likelihood of having a repeat pregnancy. We suspect that these hospitalizations were, in part, the result of complications associated with poor birth outcomes at index pregnancy (i.e., stillbirth, abortions), but given that both hospitalization and birth outcomes contributed independently to the final model, other factors may also be at play. Previously, we've shown that hospitalization during pregnancy was associated with adverse pregnancy outcomes, including preterm delivery, small for gestational age, low birth weight, and neonatal death (Kreitchmann et al., 2014).

A striking finding in our study was the high rates of adverse pregnancy outcomes in both index pregnancies (6.5\%) and repeat pregnancies (6.5\%). Despite the lower rates of alcohol use and improvement in virologic control, we did not observe any improvement in this outcome based on our matched pairs analyses but our findings are limited by the small sample size. More women were using ARVs for treatment instead of prophylaxis at the time of their repeat pregnancy in our study despite the relatively small interval between pregnancies (median 1.4 years). The guidelines in place within each country during the study required a CD4 threshold as an indication for ARVs as treatment and ARVs were continued after delivery if the women qualified for lifelong treatment. It is unknown if the strategy of lifelong HAART initiated at time of pregnancy, regardless of CD4 counts (WHO Option $\mathrm{B}+$ ) will lead to improved repeat pregnancy outcomes. This possible benefit must be balanced against concerns for reduced adherence rates in postpartum women and the potential for development of viral resistance (Kreitchmann et al., 2012; Mellins et al., 2008; Nachega et al., 2012).

Identification of characteristics associated with repeat pregnancy should assist clinicians and policy makers in targeting their reproductive counseling and planning efforts to those who may benefit the most. Many HIV-1-infected women want to become pregnant, others desire another child but not immediately, and still others may not want to become pregnant again. Predictive factors and women's expressed intentions can facilitate counseling around pregnancy planning, contraception options (reversible or non-reversible) and preconception care, as appropriate, in addition to ensuring HIV-specific care to optimize their health outcomes and prevent mother-to-child transmission.

Our study may have underestimated the frequency of repeat pregnancies because it depended upon voluntary re-enrollment at the time of the repeat pregnancy. Additionally, 153 women were excluded from the analysis because they either participated at sites which enrolled clients for less than one year $(n=41)$ or they delivered their index pregnancy within one year of the site's last enrollment $(n=112)$ and the authors felt that this did not allow 
sufficient time for re-enrollment with a subsequent pregnancy. That said, none of the 153 women excluded from the analysis presented with a second pregnancy prior to site closeout. Additionally, the median interval between index delivery and enrollment with a subsequent pregnancy was 1.4 years. Including these women would have diluted the predictive value of the risk factors, biasing our results towards the null.

The study was also unable to comment on pregnancy intentions since this information was not collected. Biological, social and cultural factors influence reproductive desires and behaviors and in HIV-infected women, reproductive desires and behaviors may also be influenced by their health and disclosure status, perceived risk of mother-to-child transmission, and the knowledge and attitude of their health care providers (Blair et al., 2004; Craft, Delaney, Bautista, \& Serovich, 2007; Heard, Sitta, Lert, \& Group, 2007). Gender inequities, religion, socioeconomic status, education level and self-efficacy may each influence a woman's decision to conceive (De La Cruz, Davies, \& Stewart, 2011). While this study did not find a difference in HIV transmission rates between women who had a repeat pregnancy and those who did not, in settings where HIV transmission is high, having an infected baby may also influence a woman's decision about future pregnancies (Suryavanshi et al., 2008; Withers et al., 2013). Additionally, it's possible that enrollment in this study improved women's awareness of their reproductive choices, resulting in fewer repeat pregnancies than may occur in a real world setting.

Craft et al (2007) discussed the important influence intimate partners have in the reproductive decisions of women. Emotional and economic aspects could influence women's desire to be pregnant again, such as fear of abandonment or rejection if a pregnancy does not occur or the inability to effectively negotiate sexual intercourse or contraceptive use, particularly among women who are economically reliant on their partners Similarly, the partner's own HIV status, his knowledge of the woman's status, and possible discordancy may influence his desire for another child. Although we did not evaluate the partners' influence on the occurrence of repeat pregnancy among the HIV-infected women in this study, it might be important for the clinicians to address this issue when working with couples in which one or both are infected with HIV.

In conclusion, we found that repeat pregnancies were more common among HIV-infected women who were younger, had required hospitalization during their index pregnancy or up to 6 months postpartum, or whose index pregnancies did not result in a live birth. Providers who care for HIV-infected women should be aware of these characteristics associated with repeat pregnancies to better target women who would benefit from reproductive counseling.

\section{Acknowledgments}

Principal investigators, co-principal investigators, study coordinators, coordinating center representatives, and NICHD staff include: Argentina: Buenos Aires: Marcelo H. Losso, Irene Foradori, Alejandro Hakim, Erica Stankievich, Silvina Ivalo (Hospital General de Agudos José María Ramos Mejía); Brazil: Belo Horizonte: Jorge A. Pinto, Victor H. Melo, Fabiana Kakehasi, Beatriz M. Andrade (Universidade Federal de Minas Gerais); Caxias do Sul: Rosa Dea Sperhacke, Nicole Golin, Sílvia Mariani Costamilan (Universidade de Caxias do Sul/Serviço Municipal de Infectologia); Nova Iguacu: Jose Pilotto, Luis Eduardo Fernandes, Gisely Falco (Hospital Geral Nova de Iguacu - HIV Family Care Clinic); Porto Alegre: Rosa Dea Sperhacke, Breno Riegel Santos, Rita de Cassia Alves Lira (Universidade de Caxias do Sul/Hospital Conceição); Rosa Dea Sperhacke, Mario Ferreira Peixoto, Elizabete Teles (Universidade de Caxias do Sul/Hospital Fêmina); Regis Kreitchmann, Luis Carlos Ribeiro, 
Fabrizio Motta, Debora Fernandes Coelho (Irmandade da Santa Casa de Misericordia de Porto Alegre); Ribeirão Preto: Marisa M. Mussi-Pinhata, Geraldo Duarte, Adriana A. Tiraboschi Bárbaro, Conrado Milani Coutinho, Fabiana Rezende Amaral, Anderson Sanches de Melo (Hospital das Clínicas da Faculdade de Medicina de Ribeirão Preto da Universidade de São Paulo); Rio de Janeiro: Ricardo Hugo S. Oliveira, Elizabeth S. Machado, Maria C. Chermont Sapia (Instituto de Puericultura e Pediatria Martagão Gesteira); Esau Custodio Joao, Leon Claude Sidi, Maria Leticia Santos Cruz, Maria Isabel Gouvêa, Mariza Curto Saavedra, Clarisse Bressan, Fernanda Cavalcanti A. Jundi (Hospital dos Servidores do Estado); São Paulo: Regina Celia de Menezes Succi, Prescilla Chow (Escola Paulista de Medicina- Universidade Federal de São Paulo); Peru: Lima: Jorge O. Alarcón Villaverde (Instituto de Medicina Tropical "Daniel Alcides Carrión”- Sección de Epidemiología, UNMSM), Carlos Velásquez Vásquez (Instituto Nacional Materno Perinatal), César Gutiérrez Villafuerte (Instituto de Medicina Tropical "Daniel Alcides Carrión"- Sección de Epidemiología, UNMSM); Data Management and Statistical Center: Yolanda Bertucci, Rachel Cohen, Laura Freimanis Hance, René Gonin, D. Robert Harris, Roslyn Hennessey, James Korelitz, Margot Krauss, Sue Li, Karen Megazzini, Orlando Ortega, Sharon Sothern de Sanchez, Sonia K. Stoszek, Qilu Yu (Westat, Rockville, MD, USA); NICHD: George K. Siberry, Rohan Hazra, Lynne M. Mofenson, Jennifer S. Read, D. Heather Watts (Eunice Kennedy Shriver National Institute of Child Health and Human Development, Bethesda, Maryland, USA).

Source of Financial Support: This work was supported by the Eunice Kennedy Shriver National Institute of Child Health and Human Development (NICHD) Contracts N01-HD-3-3345 (2002-2007), HHSN267200800001C (2007-2012), and HHSN275201300003C (2012-2017).

\section{References}

Aaron E, Bonacquisti A, Mathew L, Alleyne G, Bamford LP, Culhane JF. Small-for-gestational-age births in pregnant women with HIV, due to severity of HIV disease, not antiretroviral therapy. Infect Dis Obstet Gynecol. 2012; 2012:135030.doi: 10.1155/2012/135030 [PubMed: 22778533]

Blair JM, Hanson DL, Jones JL, Dworkin MS. Trends in pregnancy rates among women with human immunodeficiency virus. Obstet Gynecol. 2004; 103(4):663-668. 103/4/663 [pii]. DOI: 10.1097/01.AOG.0000117083.33239.b5 [PubMed: 15051556]

Bryant AS, Leighty RM, Shen X, Read JS, Brouwers P, Turpin DB, ... Tuomala RE. Predictors of repeat pregnancy among HIV-1-infected women. J Acquir Immune Defic Syndr. 2007; 44(1):87-92. DOI: 10.1097/01.qai.0000243116.14165.52 [PubMed: 17091023]

Craft SM, Delaney RO, Bautista DT, Serovich JM. Pregnancy decisions among women with HIV. AIDS Behav. 2007; 11(6):927-935. DOI: 10.1007/s10461-007-9219-6 [PubMed: 17323122]

De La Cruz NG, Davies SL, Stewart KE. Religion, relationships and reproduction: correlates of desire for a child among mothers living with HIV. AIDS Behav. 2011; 15(6):1233-1242. DOI: 10.1007/ s10461-010-9788-7 [PubMed: 20714924]

Ekouevi DK, Coffie PA, Becquet R, Tonwe-Gold B, Horo A, Thiebaut R, ... Abrams EJ. Antiretroviral therapy in pregnant women with advanced HIV disease and pregnancy outcomes in Abidjan, Cote d'Ivoire. AIDS. 2008; 22(14):1815-1820. DOI: 10.1097/QAD.0b013e32830b8ab9 [PubMed: 18753864]

French CE, Cortina-Borja M, Thorne C, Tookey PA. Incidence, patterns, and predictors of repeat pregnancies among HIV-infected women in the United Kingdom and Ireland, 1990-2009. J Acquir Immune Defic Syndr. 2012; 59(3):287-293. DOI: 10.1097/QAI.0b013e31823dbeac [PubMed: 22227490]

Friedman RK, Bastos FI, Leite IC, Veloso VG, Moreira RI, Cardoso SW, ... Grinsztejn B. Pregnancy rates and predictors in women with HIV/AIDS in Rio de Janeiro, Southeastern Brazil. Rev Saude Publica. 2011; 45(2):373-381. [PubMed: 21412574]

Gange SJ, Barron Y, Greenblatt RM, Anastos K, Minkoff H, Young M. ... Women's Interagency, H. I. V. S. C. S. G. Effectiveness of highly active antiretroviral therapy among HIV-1 infected women. J Epidemiol Community Health. 2002; 56(2):153-159. [PubMed: 11812817]

Heard I, Sitta R, Lert F. Group VS. Reproductive choice in men and women living with HIV: evidence from a large representative sample of outpatients attending French hospitals (ANRS-EN12-VESPA Study). AIDS. 2007; 21(Suppl 1):S77-82. DOI: 10.1097/01.aids.0000255089.44297.6f [PubMed: 17159592]

Kline A, Strickler J, Kempf J. Factors associated with pregnancy and pregnancy resolution in HIV seropositive women. Soc Sci Med. 1995; 40(11):1539-1547. 0277953694002807 [pii]. [PubMed: 7667658] 
Kreitchmann R, Harris DR, Kakehasi F, Haberer JE, Cahn P, Losso M. ... Team, N. L. S. Antiretroviral adherence during pregnancy and postpartum in Latin America. AIDS Patient Care STDS. 2012; 26(8):486-495. DOI: 10.1089/apc.2012.0013 [PubMed: 22663185]

Kreitchmann R, Li S, Melo V, Fernandes Coelho D, Watts D, Joao E, ... Siberry G. Predictors of adverse pregnancy outcomes in women infected with HIV in Latin America and the Caribbean: a cohort study. BJOG. 2014; doi: 10.1111/1471-0528.12680

Kupka R, Kassaye T, Saathoff E, Hertzmark E, Msamanga GI, Fawzi WW. Predictors of stillbirth among HIV-infected Tanzanian women. Acta Obstet Gynecol Scand. 2009; 88(5):584-592. DOI: 10.1080/00016340902835901 [PubMed: 19306132]

Marcellin F, Protopopescu C, Abe C, Boyer S, Blanche J, Ongolo-Zogo P. ... Group, E. S. Desire for a child among HIV-infected women receiving antiretroviral therapy in Cameroon: results from the national survey EVAL (ANRS 12-116). AIDS Care. 2010; 22(4):441-451. DOI: 10.1080/09540120903202913 [PubMed: 20140791]

Massad LS, Springer G, Jacobson L, Watts H, Anastos K, Korn A, ... Minkoff H. Pregnancy rates and predictors of conception, miscarriage and abortion in US women with HIV. AIDS. 2004; 18(2): 281-286. 00002030-200401230-00018 [pii]. [PubMed: 15075546]

Mellins CA, Chu C, Malee K, Allison S, Smith R, Harris L, ... Larussa P. Adherence to antiretroviral treatment among pregnant and postpartum HIV-infected women. AIDS Care. 2008; 20(8):958968. DOI: 10.1080/09540120701767208 [PubMed: 18608073]

Nachega JB, Uthman OA, Anderson J, Peltzer K, Wampold S, Cotton MF, ... Mofenson LM. Adherence to antiretroviral therapy during and after pregnancy in low-income, middle-income, and high-income countries: a systematic review and meta-analysis. AIDS. 2012; 26(16):2039-2052. DOI: 10.1097/QAD.0b013e328359590f [PubMed: 22951634]

Paiva V, Santos N, Franca-Junior I, Filipe E, Ayres JR, Segurado A. Desire to have children: gender and reproductive rights of men and women living with HIV: a challenge to health care in Brazil. AIDS Patient Care STDS. 2007; 21(4):268-277. DOI: 10.1089/apc.2006.0129 [PubMed: 17461722]

Read JS, Cahn P, Losso M, Pinto J, Joao E, Duarte G. ... Group, N. P. S. Management of human immunodeficiency virus-infected pregnant women at Latin American and Caribbean sites. Obstet Gynecol. 2007; 109(6):1358-1367. DOI: 10.1097/01.AOG.0000265211.76196.ac [PubMed: 17540808]

Read JS, Duarte G, Hance LF, Pinto J, Gouvea MI, Cohen RA. ... Group, N. P. S. The NICHD International Site Development Initiative perinatal cohorts (2002-09). Int J Epidemiol. 2012; 41(3):642-649. DOI: 10.1093/ije/dyr024 [PubMed: 21357185]

Suryavanshi N, Erande A, Pisal H, Shankar AV, Bhosale RA, Bollinger RC, ... Sastry J. Repeated pregnancy among women with known HIV status in Pune, India. AIDS Care. 2008; 20(9):11111118. 794152206 [pii]. DOI: 10.1080/09540120701842753 [PubMed: 18608074]

Watts DH, Huang S, Cohn SE, Smith L, Hitti J. Repeat pregnancies among HIV-infected women enrolled in clinical trial PACTG1022. J Acquir Immune Defic Syndr. 2009; 51(2):231-233. 00126334-200906010-00018 [pii]. DOI: 10.1097/QAI.0b013e3181a5b053 [PubMed: 19465826]

WHO. UNAIDS Report on the Global AIDS Epidemic 2012. 2012. Retrieved 16 Feb 2013, from http://www.unaids.org/en/media/unaids/contentassets/documents/epidemiology/2012/ gr2012/20121120_UNAIDS_Global_Report_2012_with_annexes_en.pdf

Withers M, Dworkin S, Harrington E, Kwena Z, Onono M, Bukusi E, ... Newmann SJ. Fertility intentions among HIV-infected, sero-concordant couples in Nyanza province, Kenya. Cult Health Sex. 2013; 15(10):1175-1190. DOI: 10.1080/13691058.2013.811289 [PubMed: 23885924]

Young S, Murray K, Mwesigwa J, Natureeba P, Osterbauer B, Achan J, ... Cohan D. Maternal nutritional status predicts adverse birth outcomes among HIV-infected rural Ugandan women receiving combination antiretroviral therapy. PLoS One. 2012; 7(8):e41934.doi: 10.1371/ journal.pone.0041934 [PubMed: 22879899] 


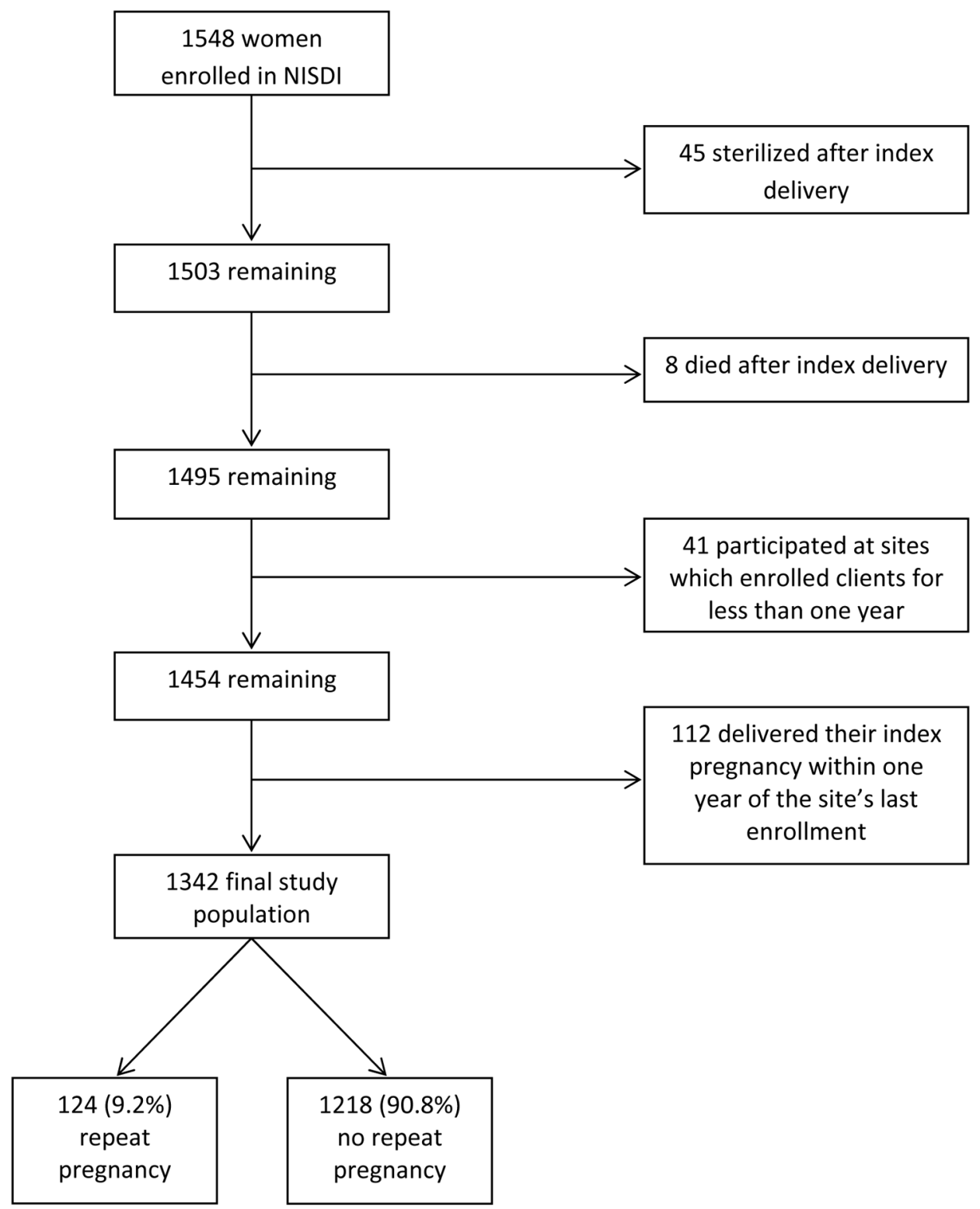

Figure 1.

Derivation of Study Population 
Table 1

Characteristics of women at enrollment into NISDI for their index pregnancy

\begin{tabular}{|c|c|c|c|}
\hline & \multicolumn{2}{|c|}{ Repeat Pregnancy } & \multirow[b]{3}{*}{$P$ value } \\
\hline & Yes & No & \\
\hline & $(\mathrm{N}=124)$ & $(\mathrm{N}=1218)$ & \\
\hline & median (IQR) & median (IQR) & \\
\hline Maternal age, years & $26(22-29)$ & $28(24-32)$ & $<0.001$ \\
\hline \multirow[t]{2}{*}{ CD4+ cell count at enrollment, cells $/ \mathrm{mm}^{3}$} & $466(275-620)$ & $403(272-581)$ & 0.14 \\
\hline & $\mathrm{n}(\%)$ & $\mathrm{n}(\%)$ & \\
\hline \multicolumn{4}{|l|}{ Race: } \\
\hline White & $78(11.9)$ & $578(88.1)$ & 0.64 \\
\hline Black & $22(9.1)$ & $221(90.9)$ & \\
\hline Mestizo & $17(11.3)$ & $134(88.7)$ & \\
\hline Other & $2(6.9)$ & $27(93.1)$ & \\
\hline Missing & 5 & 258 & \\
\hline \multicolumn{4}{|l|}{ Country: } \\
\hline Argentina & $50(16.2)$ & $259(83.8)$ & $<0.001$ \\
\hline Bahamas & $0(0.0)$ & $4(100)$ & \\
\hline Brazil & $69(7.4)$ & $865(92.6)$ & \\
\hline Mexico & $0(0.0)$ & $33(100)$ & \\
\hline Peru & $5(8.1)$ & $57(91.9)$ & \\
\hline \multicolumn{4}{|l|}{ Employment: } \\
\hline Homemaker/Unemployed/Student & $99(9.9)$ & $901(90.1)$ & 0.16 \\
\hline Employed Outside Home & $25(7.3)$ & $317(92.7)$ & \\
\hline \multicolumn{4}{|l|}{ Education, years completed: } \\
\hline $0-6$ & $33(7.8)$ & $390(92.2)$ & 0.26 \\
\hline $7-12$ & $82(9.6)$ & $769(90.4)$ & \\
\hline$\geq 13$ & $9(13.2)$ & $59(86.8)$ & \\
\hline \multicolumn{4}{|l|}{ Marital status: } \\
\hline Married/Living with partner & $93(9.4)$ & 899 (90.6) & 0.83 \\
\hline Divorced/Separated/Single/Widowed & $31(8.9)$ & $319(91.1)$ & \\
\hline \multicolumn{4}{|l|}{ CD4+ cell count at enrollment, cells $/ \mathrm{mm}^{3}$ : } \\
\hline$<200$ & $15(8.3)$ & $166(91.7)$ & 0.46 \\
\hline $200-499$ & $59(8.7)$ & $621(91.3)$ & \\
\hline 2500 & $50(10.7)$ & $417(89.3)$ & \\
\hline Missing & 0 & 14 & \\
\hline \multicolumn{4}{|l|}{ Viral load at enrollment, copies/mL: } \\
\hline$<400$ & $58(8.1)$ & $658(91.9)$ & 0.15 \\
\hline$\geq 400$ & $64(10.5)$ & $545(89.5)$ & \\
\hline Missing & 2 & 15 & \\
\hline
\end{tabular}




\begin{tabular}{|c|c|c|c|}
\hline & \multicolumn{2}{|c|}{ Repeat Pregnancy } & \multirow[b]{3}{*}{$P$ value } \\
\hline & Yes & No & \\
\hline & $(N=124)$ & $(\mathrm{N}=1218)$ & \\
\hline \multicolumn{4}{|l|}{ HIV class at baseline: } \\
\hline A & $108(9.4)$ & $1040(90.6)$ & 0.90 \\
\hline $\mathrm{B}$ & $6(7.4)$ & $75(92.6)$ & \\
\hline $\mathrm{C}$ & $10(8.8)$ & $103(91.2)$ & \\
\hline \multicolumn{4}{|c|}{ Alcohol use during index pregnancy: } \\
\hline Yes & 19 (10.6) & $160(89.4)$ & 0.49 \\
\hline No & $102(8.9)$ & $1041(91.1)$ & \\
\hline Missing & 3 & 17 & \\
\hline \multicolumn{4}{|c|}{ Tobacco use during index pregnancy: } \\
\hline Yes & $31(8.9)$ & $319(91.1)$ & 0.83 \\
\hline No & $91(9.3)$ & $884(90.7)$ & \\
\hline Missing & 2 & 15 & \\
\hline \multicolumn{4}{|c|}{ Illicit drug use during index pregnancy: } \\
\hline Yes & $11(20.8)$ & $42(79.2)$ & 0.007 \\
\hline No & $113(8.8)$ & $1176(91.2)$ & \\
\hline \multicolumn{4}{|l|}{ Mode of infection: } \\
\hline Heterosexual transmission & $118(9.2)$ & $1158(90.8)$ & 0.44 \\
\hline Other & $3(14.3)$ & $18(85.7)$ & \\
\hline Missing & 3 & 42 & \\
\hline \multicolumn{4}{|l|}{ ARV use for index pregnancy: } \\
\hline Prophylaxis & $65(9.9)$ & $591(90.1)$ & 0.44 \\
\hline Treatment & $55(8.6)$ & $585(91.4)$ & \\
\hline Missing & 4 & 42 & \\
\hline \multicolumn{4}{|c|}{ ARV experienced at enrollment: } \\
\hline Yes & $78(8.1)$ & $884(91.9)$ & 0.05 \\
\hline No & $27(12.5)$ & $189(87.5)$ & \\
\hline Missing & 19 & 145 & \\
\hline \multicolumn{4}{|c|}{ Hospitalizations (during pregnancy or up to 6 months postpartum): } \\
\hline Yes & 20 (15.6) & $108(84.4)$ & 0.01 \\
\hline No & $104(8.6)$ & $1110(91.4)$ & \\
\hline \multicolumn{4}{|l|}{ Index birth outcome: } \\
\hline Live birth & $117(8.9)$ & $1192(91.1)$ & 0.02 \\
\hline Stillbirth or abortion & $7(22.6)$ & $24(77.4)$ & \\
\hline Missing & 0 & 2 & \\
\hline \multicolumn{4}{|l|}{ Singleton: } \\
\hline Yes & $123(9.3)$ & $1198(90.7)$ & 0.71 \\
\hline No & $1(4.8)$ & $20(95.2)$ & \\
\hline \multicolumn{4}{|l|}{ Number of living children: } \\
\hline 0 & $33(10.1)$ & $294(89.9)$ & 0.39 \\
\hline 1 & $35(8.3)$ & $388(91.7)$ & \\
\hline
\end{tabular}




\begin{tabular}{cccc}
\hline & \multicolumn{2}{c}{ Repeat Pregnancy } & \\
& Yes & No & \\
\cline { 2 - 3 } & (N= 124) & (N= 1218) & P value \\
\hline 2 & $22(7.6)$ & $266(92.4)$ & \\
$3+$ & $34(11.2)$ & $270(88.8)$ & \\
Gravidity: & & & \\
1 & $19(9.5)$ & $181(90.5)$ & 0.97 \\
2 & $31(9.3)$ & $302(90.7)$ & \\
$3+$ & $74(9.1)$ & $735(90.9)$ & \\
Parity: & & & \\
0 & $30(9.9)$ & $272(90.1)$ & 0.63 \\
1 & $35(8.4)$ & $380(91.6)$ & \\
2 & $24(8.1)$ & $272(91.9)$ & \\
$3+$ & $35(10.6)$ & $294(89.4)$ & \\
\hline
\end{tabular}

ARV - antiretroviral drugs; IQR - interquartile range

p-values obtained from Fisher's exact test for categorical measures and nonparametric (Mann-Whitney) testing for continuous-scaled measures. 


\section{Table 2}

Multivariable logistic regression analysis of factors associated with repeat pregnancy among HIV-infected women enrolled in NISDI

\begin{tabular}{lcc}
\hline & OR $(\mathbf{9 5 \%} \mathbf{C I})$ & p-value \\
\hline Maternal age (1 year decrease) & $1.07(1.04-1.11)$ & $<0.0001$ \\
Hospitalizations during index pregnancy (or up to 6 months postpartum) & & \\
$\quad$ Yes & $2.0(1.2-3.4)$ & $<0.01$ \\
No & 1.0 & \\
Index birth outcome: & & \\
$\quad$ Stillbirth or abortion & $3.4(1.4-8.4)$ & $<0.01$ \\
$\quad$ Live birth & 1.0 & \\
\hline
\end{tabular}

